\title{
Approach to upper gastrointestinal bleeding - When to treat?
}

\author{
P RUTGEERTS, MD
}

\begin{abstract}
Upper gastrointestinal bleeding from peptic ulcer is a life threatening emergency. Clinical risk factors for fatal outcome have been defined, and endoscopic predictors for rebleeding have been identified. Active ulcer bleeding at endoscopy carries an $80 \%$ chance of persistent or recurrent bleeding. A nonbleeding visible vessel is associated with a $50 \%$ chance of rebleeding. These endoscopic lesions should be treated endoscopically. Failure to obtain definitive hemostasis endoscopically will necessitate emergency surgical treatment. Can J Gastroenterol 1990;4(9):647-649
\end{abstract}

Key Words: Endoscopy, Hemorrhage, Peptic ulcer, Risk factors

\section{Comment aborder l'hémorragie des voies digestives} supérieures. Quand traiter?

RESUME: L'hémorragie digestive haute provoquée par un ulcère gastroduodénal constitue une urgence qui met en jeu la vie du sujet. Les facteurs de risque cliniques menaçant le pronostic vital ont été définis et les éléments endoscopiques permettant de prédire les récidives ont été identifiés. Dans l'hémorragie ulcéreuse active sous endoscopie, les risques de saignements persistants ou récidivants s'élèvent à $80 \%$. Dans le cas d'un vaisseau visible qui ne saigne pas, l'éventualité d'une récidive atteint $50 \%$. Ces lésions endoscopiques devraient être traitées par endoscopie. L'échec de l'hémostase endoscopique définitive nécessite une intervention d'urgence.

$\mathrm{T}$ HE SEARCH FOR SAFE, EFFECTIVE and inexpensive endoscopic methods to control severe peptic ulcer bleeding continues. Upper gastrointestinal bleeding in this era of high medical technology still has an overall mortality of about $10 \%$. The incidence of this often dramatic emergency is es- timated at one in 1000 per year. Prognostic clinical factors for outcome have been clearly defined (Table 1) and have changed somewhat over the last decades as bleeding occurs more now in elderly and critically ill patients with underlying medical conditions (1-4). About 70 to $80 \%$ of patients have al-
Department of Medicine, University Hospital Gasthuisberg, Belgium

Correspondence and reprints: Dr P Rutgeerts, Associate Professor of Medicine, University Hospital Gaschuisberg, Herestraat 49, 3000 Leuven, Belgium. Telephone (016) 214225 ready stopped bleeding when admitted to hospital. No transfusion or only a few units are required. Endoscopy in these patients visualizes a nonbleeding lesion, mostly without stigmata of recent hemorrhage. The evolution will be uneventful; any aggressive therapy may harm the patient. Twenty to $30 \%$ of patients are admitted with arterial hypotension and continue to bleed or rebleed while in hospital. These patients have high transfusion requirements and are at high risk.

Severe bleeding almost always originates from peptic ulcers or from esophageal or fundic varices. In patients with severe bleeding, an upper gastrointestinal endoscopy should be performed as soon as possible after resuscitation. There is no doubt that the diagnostic

TABLE 1

Factors predicting increased mortality from upper gastrointestinal bleeding

Age older than 60 years

Presence of underlying medical problems, especially liver disease and malignancy

Persistent hypotension despite multiple transfusions

Active ulcer bleeding or nonbleeding visible vessel at endoscopy or variceal origin of bleeding

Requirement for emergency surgery 


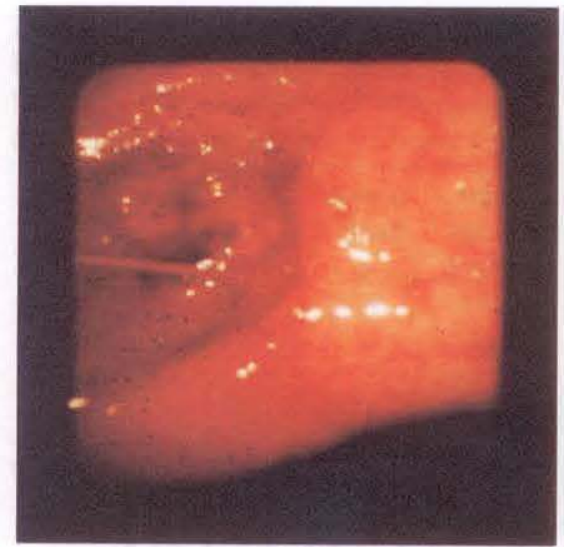

Figure 1) Prepyloric ulcer with spurting artery

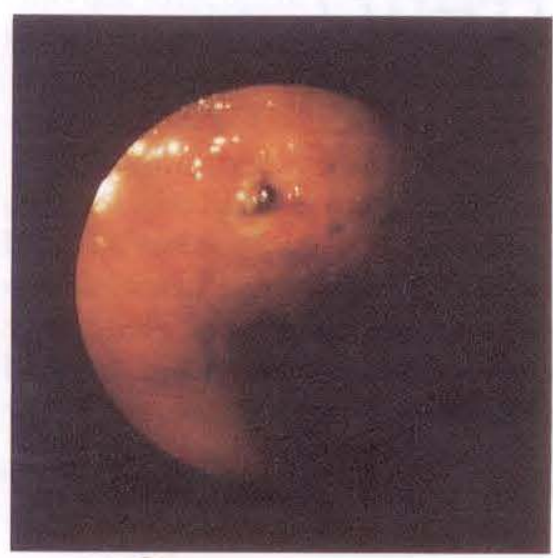

Figure 2) Nonbleeding vessel protruding from the base of a gastric ulcer

\section{TABLE 2}

\section{Current methods for hemostasis of peptic ulcer bleeding}

Thermal methods

Neodymium-YAG laser photocoagulation

Bipolar electrocoagulation (BICAP) Monopolar electrocoagulation Heater probe

Injection methods

Adrenaline 1:10,000

Adrenaline 1:10,000 + polidocoanol 1\% Absolute ethanol

yield of early endoscopy in upper gastrointestinal hemorrhage is superior to that of a barium meal. The timing of endoscopy influences the frequency of acute bleeding present at endoscopy (4). If performed within $12 \mathrm{~h}$ of admission, $41 \%$ of patients will have active bleeding. When endoscopy is performed more than $12 \mathrm{~h}$ after admission the incidence of active bleeding is

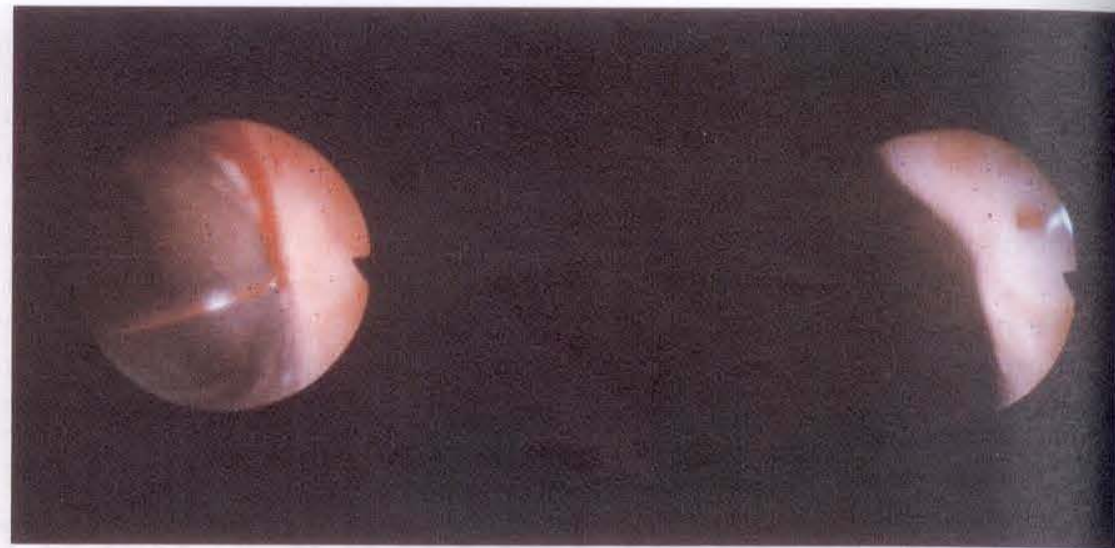

Figure 3) Ulcer with visible vessel. Due to contact with the scope arterial spurting is induced

about $30 \%$. In a survey by the American Society for Gastrointestinal Endoscopy (4), active bleeding at endoscopy was associated with a mortality rate of $16.1 \%$; if there was no active bleeding, the mortality dropped to $6.7 \%$.

The nature of the bleeding lesion has prognostic importance. Therapeutic efforts should be directed towards those patients who continue to bleed or are likely to rebleed. It is critical to identify these high risk groups.

Bleeding from esophagitis, MalloryWeiss tears, neoplasms, gastric erosions, erosive duodenitis and vascular malformations are usually mild. When peptic ulcers or varices are diagnosed at endoscopy, the finding of stigmata of recent hemorrhage predicts further bleeding.

In 1978 Foster et al (5) identified three endoscopic stigmata of recent hemorrhage as predictors of continuing or recurrent bleeding: fresh bleeding from the lesion; fresh or altered clot or black slough adherent to the lesion; and a vessel protruding from the base or margin of an ulcer. Griffiths (6) confirmed the prognostic importance of the nonbleeding visible vessel. Accurate prospective data were obtained by Storey and Swain $(7,8)$.

It is easy to identify a spurting hemorrhage (Figure 1) or a pulsating pseudoaneurysm as arterial in origin. Identification of a nonbleeding artery (Figures 2,3) is more subjective. According to Storey (7) and Swain (8), a nonbleeding artery appears on endoscopy as an elevated red or blue spot, resistant to gentle washing, often associated with a red clot and almost al- ways unique in the ulcer crater. Overall, recurrent bleeding occurred in $85 \%$ of ulcers presenting with spurting hemorrhage at endoscopy, in $51 \%$ of ulcers with a nonbleeding visible vessel, in $5 \%$ of ulcers with other stigmata of recent hemorrhage, and in $0 \%$ of ulcers with. out stigmata. These data were chal. lenged recently by Wara (9), who found a lower rebleeding rate $(32 \%)$ of ulcers with a nonbleeding visible vessel. He suggested that a visible vessel carries a high rebleeding risk only when an 00 : ing hemorrhage or overlying clot is present at endoscopy. Another recent study by Bornman (10) showed that the association of shock with importantendoscopic signs is a stronger predictor of rebleeding than shock or important signs alone.

One decade ago patients with severe upper gastrointestinal hemorrhage were candidates for emergency surgery, carrying a mortality of approximately $25 \%$ in contrast with the $3 \%$ mortality in elective surgery for upper gastrointes. tinal hemorrhage.

Several methods of hemostasis in upper gastrointestinal bleeding have been developed and evaluated in animal ex. periments, human pilot studies, controlled clinical trials and randomized comparative studies.

The ultimate benefit of endoscopic hemostasis for the patient with upper gastrointestinal hemorrhage is reduc. tion of mortality, but benefit might also encompass lowered morbidity and reduced cost of patient care.

Efficacious endoscopic hemostasis (Table 2) would reduce mortality due to 


\section{TABLE 3}

Major risk factors for unsuccessful endoscopic hemostasis for bleeding ulcers

Too large vessel calibre (serosal versus submucosal vessel)

Inaccessibility because of location or scarring

Giant ulcer with disappearance of tissue elasticity

Inappropriate techniques

Underlying coagulation disorders Diagnostic failure

bleeding; by avoiding emergency surgery it would also decrease often lethal postoperative complications.

Many deaths from gastrointestinal bleeding seem to be inevitable. Improvement of current mortality figures, therefore, will not easily be achieved.

Endoscopy may harm the bleeding patient. Therapeutic endoscopy should be withheld from patients who do not continue to bleed. Patients can develop a complication from the diagnostic procedure or from endoscopic hemostasis. Delayed surgery in the patient requiring it may also be harmful.

Early endoscopy in upper gastrointestinal bleeding is associated with a higher complication rate than is the elective procedure. Perforation rarely occurs during diagnostic endoscopy, but endoscopic hemostasis is associated with a 1 to $2 \%$ risk of perforation.

More common are cardiopulmonary complications. Pulmonary aspiration

\section{REFERENCES}

1. Allan R, Dykes P. A study of the factors influencing mortality rates from gastrointestinal hemorrhage. Q J Med (NS) 1976;180:533-8.

2. Avery-Jones F. Hematemesis and melaena with special reference to causation and to factors influencing the mortality from bleeding peptic ulcers. Gastroenterology 1956;30:166-9.

3. Schiller KFR, Truelove SG, Williams DG. Haematemesis and melaena, with special reference to factors influencing outcome. Br Med J 1970;2:7-14.

4. Silverstein FE, Gilbert DA, Tedesco FJ. The national ASGE survey on

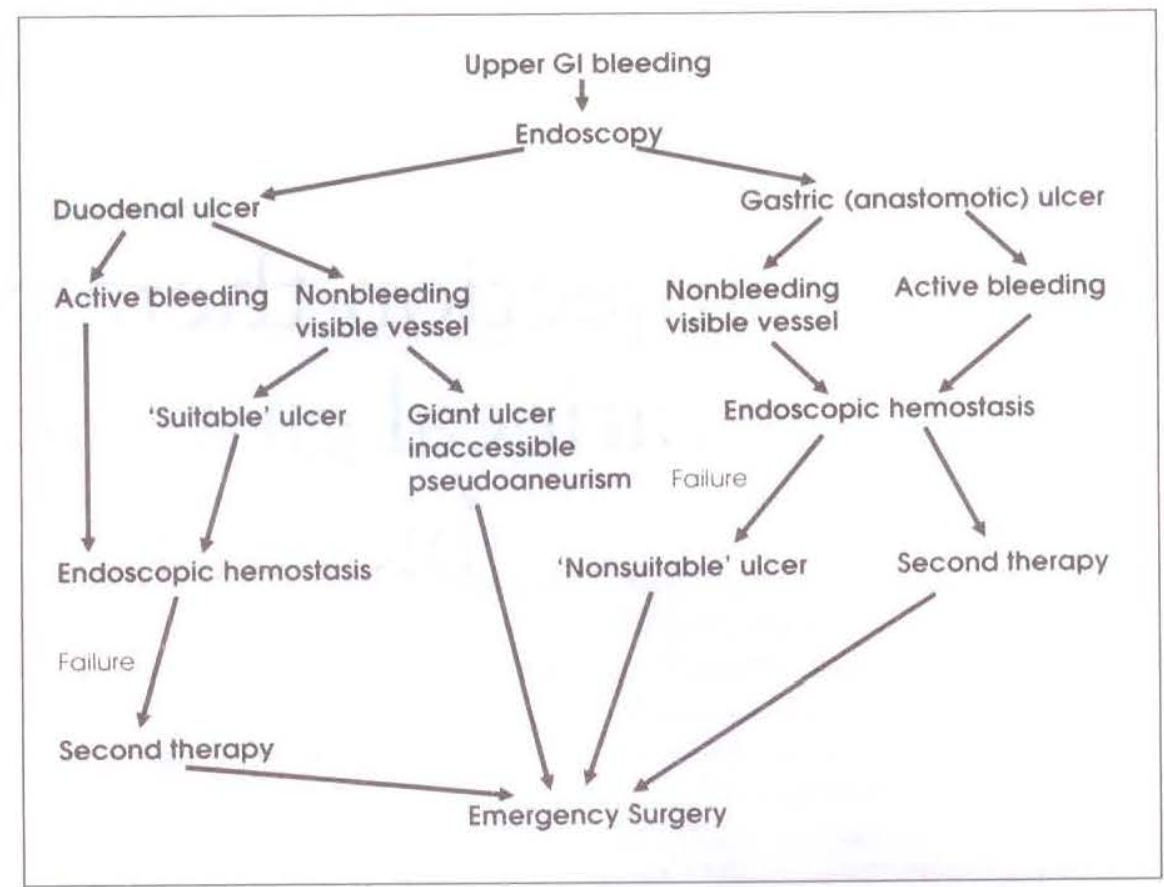

Figure 4) Algorithm for endoscopic and surgical approach in upper gastrointestinal ulcer bleeding

should be avoided in the heavy bleeder by cleansing of the stomach before premedication, or by tracheal intubation. If aspiration has occurred, bronchial toilet and antibiotics are imperative. Cardiac arrhythmias due to ischemia and hypoxemia frequently occur in the bleeding elderly patient, but are usually without sequelae.

One must also know the limitations of endoscopic hemostasis. The authors' studies (unpublished data) have clearly shown that the results of endoscopic therapy are not satisfying in a number

upper gastrointestinal bleeding. Parts 13. Gastrointest Endosc 1981;27:73-102.

5. Foster DN, Miloszewski KJA, Losowsky MS. Stigmata of recent hemorrhage in diagnosis and prognosis of upper gastrointestinal bleeding. $\mathrm{Br}$ Med J 1978;1:1173-7.

6. Griffiths WJ, Neumann DA, Welsh JD. The visible vessel as an indicator of uncontrolled or recurrent gastrointestinal haemorrhage. $\mathrm{N}$ Engl J Med 1979;300:411-3.

7. Storey DW, Bown SG, Swain CP. Endoscopic prediction of recurrent bleeding of peptic ulcers. N Engl J Med 1981;305:915-6. of subgroups of patients. Large ulcers penetrating serosal arteries are difficult to treat with success, eg, ulcers of the posterior duodenal wall penetrating to the retroduodenal artery. Some locations are difficult, including postbulbar and subcardial ulcers. Small ulcers with large vessels (Dieulafoy's ulcers) require repeated therapy or surgery. The causes of unsuccessful hemostasis are summarized in Table 3 . The authors propose a management plan for patients with upper gastrointestinal ulcer bleed in Figure 4.

8. Swain CP, Storey DW, Bown SG, et al. Nature of the bleeding vessel in recurrently bleeding gastric ulcers. Gastroenterology 1986;90:595-608.

9. Wara P. Endoscopic prediction of major rebleeding - A prospective study of stigmata of hemorrhage in bleeding ulcers. Gastroenterology 1985;88:1209. 14.

10. Bornman PC, Theodorou NA, Shuttleworth RD, Essel HP, Marks IN. Importance of hypovolemic shock and endoscopic signs in predicting recurrent hemorrhage from peptic ulceration: A prospective evaluation. Br Med J 1985;291:245-7. 


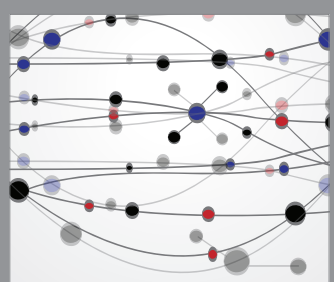

The Scientific World Journal
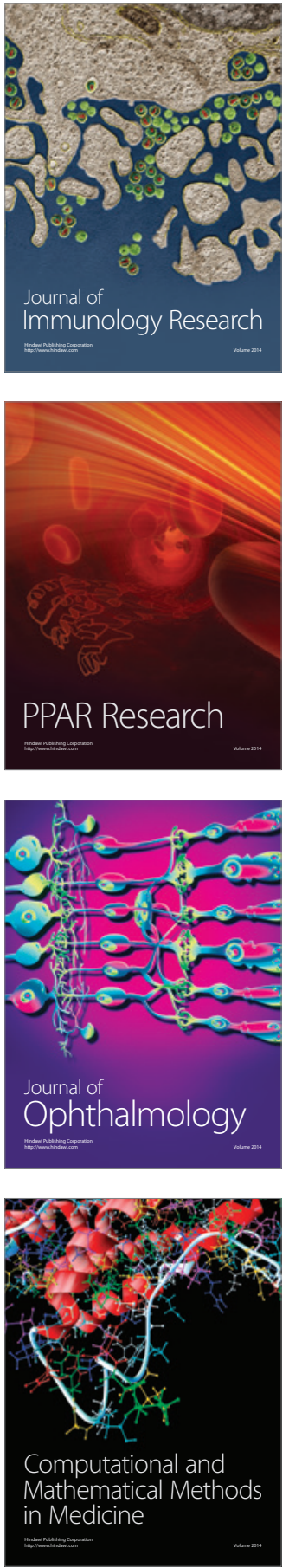

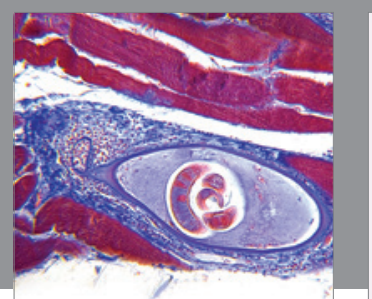

Gastroenterology Research and Practice

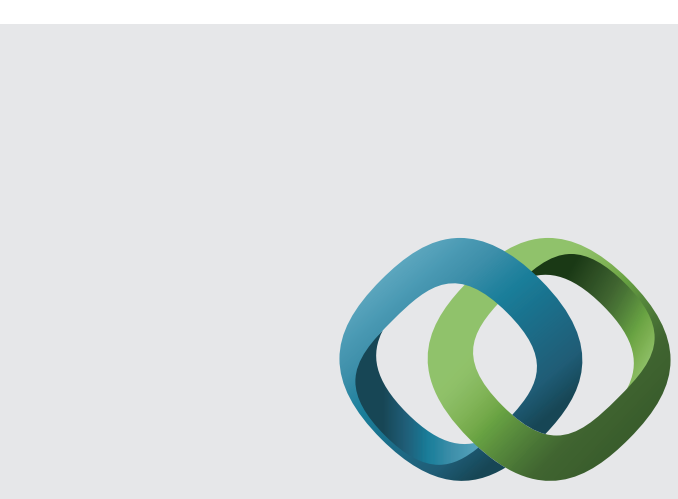

\section{Hindawi}

Submit your manuscripts at

http://www.hindawi.com
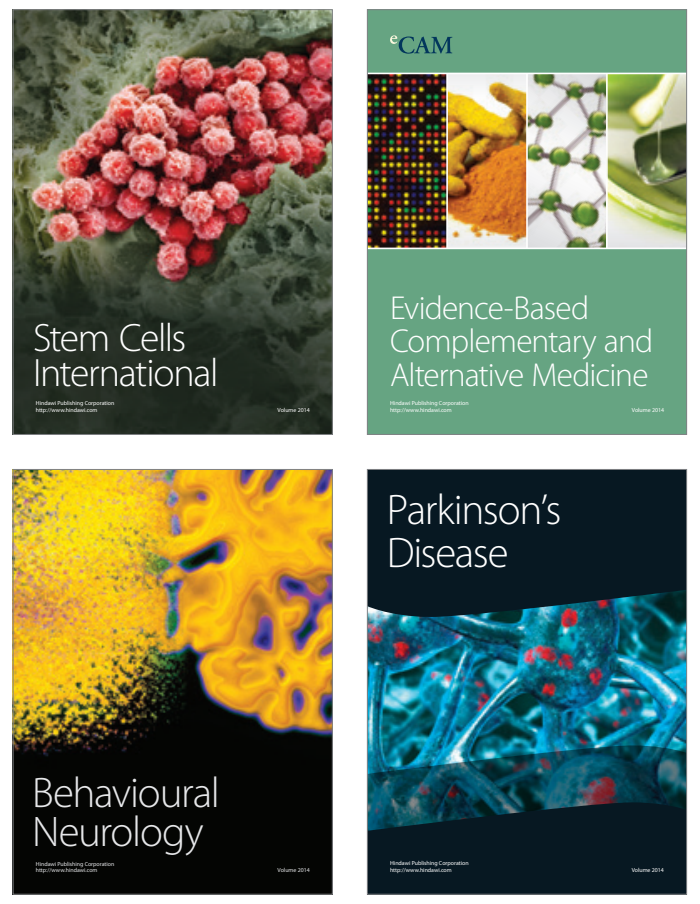
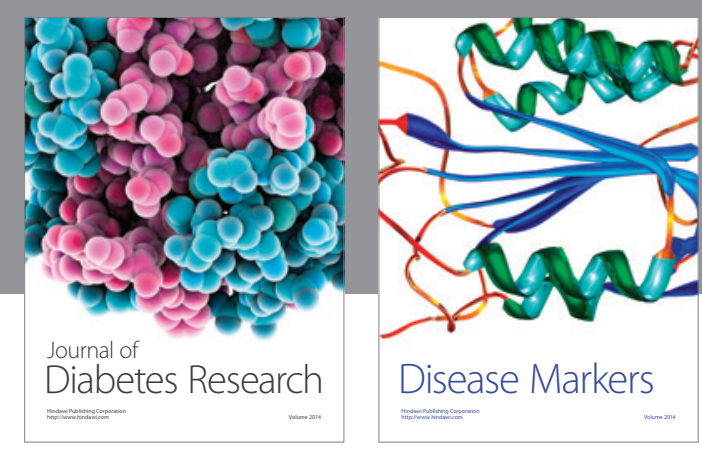

Disease Markers
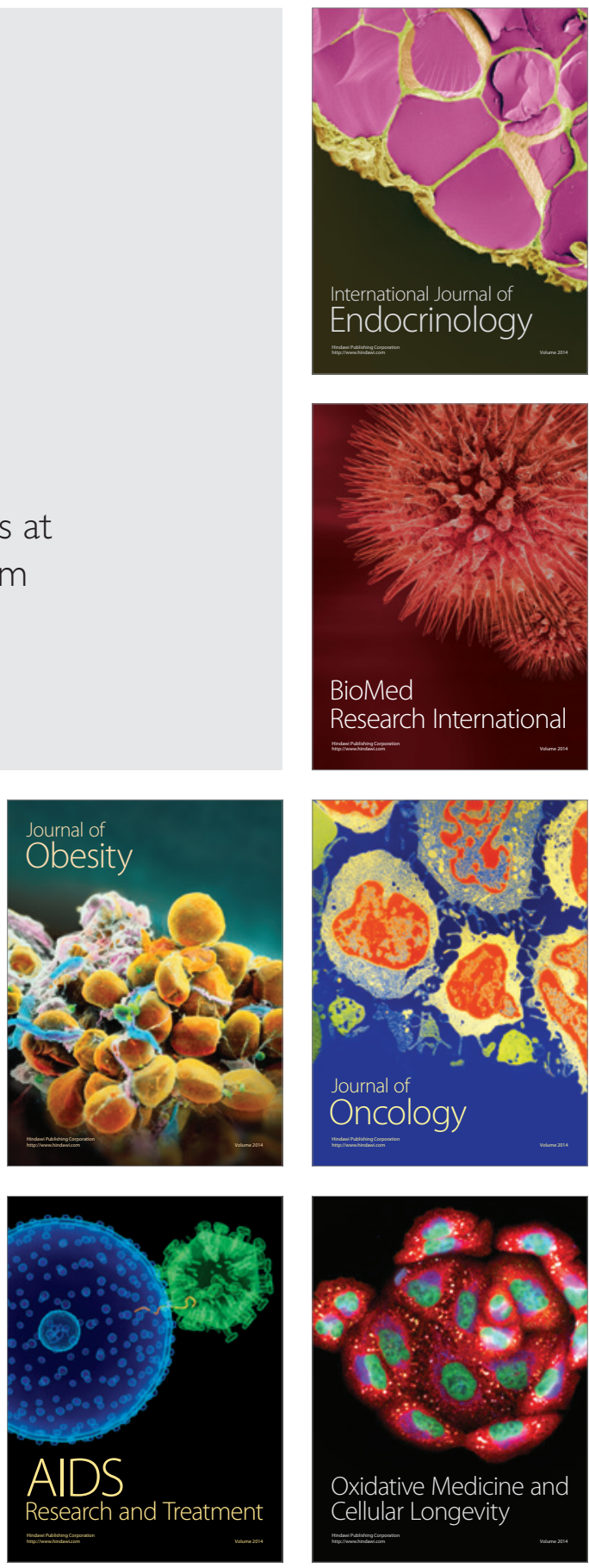